\title{
Immediate Echolalia and the Interactive Behaviour of Autistic Children
}

\author{
Ingrid van Zyl B.(Log) (Pret) \\ Erna Alant D.Phil (Pret) \\ Isabel C. Uys D.Phil (Pret) \\ Department Speech Pathology and Audiology, \\ University of Pretoria
}

\begin{abstract}
This research examined whether echolalia and interactive behaviour in autistic children could function within a communicative system. Four autistic children were videotaped individually in interaction with a familiar adult. A categorical system was designed whereby the children's interactive behaviour could be rated. It was found that the immediate echolalia is far more than a meaningless repesition of words. The utterances are relevant, displaying the conveyance of meaningful information and the maintenance of social interaction. Conclusions were drawn on the facilitation of communication through modification and expansion of immediate echolalia.
\end{abstract}

\section{OPSOMMING}

Die doel van hierdie ondersoek is om vas te stel of eggolalie en interaksiegedrag in outistiese kinders binne 'n kommunikasiesisteem funksioneer. Individuele video-opnames van die interaksie van vier outistiese kinders met 'n bekende volwassene is gemaak. ' $n$ Kategoriese sisteem is ontwerp vir die beoordeling van die kinders se interaksiegedrag. Bevindings dui daarop dat onmiddellike eggolalie meer is as slegs die betekenislose herhaling van woorde. Die uitinge is meestal relevant en dui op die oordrag van betekenisvolle informasie en die behoud van sosiale interaksie. Gevolgtrekkings word gemaak oor die fasilitasie van kommunikasie deur die modifikasie en uitbreiding van onmiddellike eggolalie.

Of the language abnormalities which are quoted as primary criteria in the diagnosis of autism, immediate echolalia is the most frequently cited characteristic of autistic children who have some verbal expressive ability (Prizant \& Duchan, 1982). Echolalia is generally defined, by many authors (Fay, 1980; Hurtig et al., 1982; Wing, 1976) as the meaningless and automatic production of words, without understanding, that are an exact or partial copy of those originally spoken by another person.

There is a certain controversy surrounding the significance of immédiate echolalia for the autistic child. Behaviourally orientated researches consider echolalia as an undesirable symptom of the language behaviour of autistic children (Koegal et al., 1974). They consider echolalia as a communication disorder in itself and therefore advocate its extinction or replacement through the use of behaviour modification procedures (Lovaạs, 1977).

A recent trend in research has been to consider immediate echolalia in terms of how it may function for autistic children (Prizant \& Duchan, 1982). Fay (1973), suggests that immediate echolalia enables the autistic child to maintain social interaction in the face of a severe comprehension problem. Philips \& Dyer (1977), hypothesize that immediate echolalia is a late onset form of normal imitative functioning in young children and that with the appropriate intervention programme, the echolalia becomes useful to the child and gives him access to an experience with the complexities of grammar.

Considering the diversity of views held in relation to immediate echolalia and how it may function for autistic children, it is of contention that these children, who have a severe language problem are attempting to communicate and interact socially with other people to the best of their limited capabilities. During the past few years (Schuler, 1980) much work has been carried out on the pragmatic aspects of language. Emphasis has shifted away from a purely structural view toward a more functional approach.

Prizant \& Duchan (1982) analyzed immediate echoic utterances according to gaze behaviour and other non-verbal components such as general body orientation and manipulation of objects. Seven distinct categories of echolalia were derived and a function was attributed to each structural category, namely: non-focussed; turn-taking; declarative; rehearsal; self-regulatory; yes-answer; and request function.

However, a functional approach does have certain limitations in that it requires an interpretation of the autistic child's communication intent in a particular situation. Contextual cues (e.g. the reaction of the listener) are frequently used as indicators of the function of a particular verbalization (Dore, 1978). One is often inclined to interpret verbalizations according to one's own perspective. Schuler (1980) emphasizes, that in judging the relevance of verbalizations one should guard against vver-interpretation. These overinterpretations become even more tempting when observed speech behaviours resemble our own speech.

Consideration of the conflicting vicws of rescarchers in relation to the function of immediate echolalia for the autistic child and the limitations of a functional approach has led to this research. The main focus of this study is to determine whether immediate echolalia can function within a communication system. Echoic and non-echoic utterances are viewed within a framework where the initiation of utterances, turn-taking, and the segmental features of the utterances are considered to determine the relevance of the autistic child's utterances; analyzing the echoic and non-echoic behaviour in natural communicative interactions considering situational factors and nonverbal behaviours co-occurring with the production of echoic utterances. 


\section{METHOD}

AIMS

To determine whether the verbal utterances, in particular the immediate echoic responses of autistic children, have communicative relevance as described by Prizant and Duchan (1982).

To construct a categorical system whereby interactive behaviour and immediate echolalic responses of autistic children can be analyzed as relevant or irrelevant in communication.

\section{SUBJECTS}

A preliminary study was carried out by the examiner to select suitable subjects and to clarify the procedural aspects of the experiment.

The 4 subjects who participated in the experiment were selected from the Unica School for Autistic Children in Pretoria. Each subject had to be diagnosed as autistic by a professional evaluation team comprising two psychiatrists; a clinical psychologist; a speech clinician; the principal of the Unica School and one teacher. The Department of National Education (1971) requires that each child admitted to the Unica School must fulfil the four essential criteria of the autistic syndrome (Rutter, 1974):

- onset of the disorder prior to thirty months of age;

- disturbances of language and communication;

- persistent, ritualistic and compulsive behaviour;

- disturbed social relationship

Each child must also display a minimum of seven of the 14 core symptoms noted by Clancy et al. (1964) which are most persistently present in the syndrome of infantile autism and are regarded as the major manifestations of the disease. To qualify for participation in the experiment, each child had to demonstrate that at least $25 \%$ of all verbal productions were echoic responses (Prizant and Duchan, 1982). study was on functional communication rather than the relationship between this and cognition.

\section{PROCEDURE}

During interaction with the children it was noted that they did not make contact with the examiner. Therefore the resident speech clinician participated as the interlocutor in the experiment. The structured activities designed to elicit verbal responses from the children during the interaction with the interlocutor, were selected according to a preliminary study. The same activities were used for all four subjects. Although this may seem inappropriate due to the wide age and mental status range, these activities were recommended by the resident speech clinician and the children's teachers, since eating and drinking activities are enjoyed by children of all ages.

Data collection was extended over a three day period for each child with a one day interval. Each child was videotaped in interaction with the interlocutor on two occasions, each 30 minutes in length, to ensure that a reliable sample of the child's communicative abilities was obtained.

The situation involved direct interaction between the interlocutor and the child. During the interaction the interlocutor was directed to interact/communicate with each child as naturally as possible and to indirectly encourage the child to communicate by eliciting the child's interest in the activities provided.

\section{ANALYSIS: CATEGORICAL SYSTEM}

A preliminary study indicated that the categorical system described by Prizant $\&$ Duchan (1982) was highly complex and subjective in the interpretation of the function of immediate echolalia. Therefore the examiner constructed a categorical system for the purpose of analyzing the relevance and irrelevance of the children's utterances, including their echolalic responses based on interpretation

Table 1 Criteria for subject selection

\begin{tabular}{|l|l|l|l|l|}
\hline CRITERION & SUBJECT 1 & SUBJECT 2 & SUBJECT 3 & SUBJECT 4 \\
\hline $\begin{array}{l}\text { Mental Status } \\
\text { Griffiths Mental } \\
\text { Development Scales }\end{array}$ & 24 months & non-testable & 29 months & 36 months \\
\cline { 2 - 5 } Age & $5: 8$ & $8: 3$ & $8: 5$ & $11: 1$ \\
\hline Previous therapy & None & $\begin{array}{r}*-\text { auditory perception } \\
\text { receptive and } \\
\text { expressive language } \\
\text { stimulation }\end{array}$ & $\begin{array}{l}*-\text { auditory perception } \\
\text { receptive and } \\
\text { expressive languge } \\
\text { expansion }\end{array}$ & None \\
\hline Language & Afrikaans & $\begin{array}{l}\text { Afrikaans } \\
\text { Afrikaans }\end{array}$ & Afrikaans \\
\hline
\end{tabular}

* During speech therapy echoic utterances were accepted but not encouraged by the speech clinician.

Table 1 presents a number of the criteria used during subject selection. The age of the subjects was not deemed a significant factor since the study was focussed on the relevance of the interactive behaviour and particularly, immediate echolalia, and not on the performance of a specific age group.

Although reference is made to the mental status of each subject, this too was not considered a significant factor. The focus of the of behavioural aspects co-occurring with the children's utterances (sec Table 2).

Due to the complex nature of the categorization procedures, data analysis was restricted to 20 utterances in each interaction. The first 20 utterances of each interlocutor - child interaction were selected since the children displayed éxcellent co-operation and attention at the beginning of each interaction.

The South African Journal of Communication Disorders, Vol. 32, 1985 
1. Initiation:A spontaneous, original utterance created by the child and not an echoic response.

2. Delayed Echolalia: A repetition of stored utterances which the child has heard some time before, in a new and usually inappropriate context (Fay, 1980).

3. Turn-taking: Smooth interchanges between the child and the interlocutor (Prutting, 1982); Each utterance in this category is also coded according to whether the turn was:-

- Verbal: Indicating that the utterance is not accompanied by any non-verbal behaviour.

- Verbal and non-verbal: Indicating that the child's verbal response is accompanied by one or more of the following non-verbal behaviours:

- eye contact with the interlocutor

- gaze behaviour at the object,

- head movements,

- smiling, and

- deliberate gestural actions;

4. Relevance: The child's utterance is either designated as a self-directed or as an other-directed response;

- Self-directed: A self-directed utterance is used by the child to monitor his action, or to focus control on his actions, or used for planning what he will do next (Tough, 1977).

- Other-directed: An other-directed utterance is directed at the interlocutor by the child for demonstrating the actions he requests, instructing, forward planning, and anticipating collaborative action (Tough, 1977).

The relevance of the utterance is coded by a positive or a negative rating. A positive rating indicates that the child's utterance displays communicative intent.

Indicators of Communicative Intent: - any of the following behaviour associated with the verbal response:

- Eye contact with the interlocutor. According to Argyle (1973), eyes provide crucial information about where the person is looking, and the area around the eyes is extremely expressive. One looks to obtain information and to send signals; this is all concerned with the flow of information needed to perform the social skills of interacting.

- Appropriate gaze behaviour at the object. Direction of gaze shows the direction of that person's attention (Argyle, 1973).

- Deliberate and voluntary actions. Hand movements especially, play a role in social interaction. Their principle function is as illustrators accompanying speech, and augmenting it when verbal skills are inadequate (Argyle, 1973).

- The echoic response is functionally relevant to the task, or to the child's self-directed utterance, or to the interlocutor's utterance indicating communicative intent.

A negative rating indicates that the child's response is irrelevant and a purely meaningless repetition; devoid of any indication of communicative intent.

5. Linguistic Segmental Features: The utterance is rated according to whether the child changes or exactly repeats the linguistic segmental features of the model utterance.

- Changed: The child uses some of the interlocutor's words or either adds, deletes, or substitutes elements and is therefore not an exact repetition of the model utterance (Prizant and Duchan, 1982).

- Same: The child gives an exact, complete or partial repetition of the interlocutor's model utterance.

6. Non-segmental Features: The non-segmental features of the child's echoic response are rated according to the similarity in intonation, stress, speaking rate, duration, and voice to the model utterance. Linguists recognize that timing, pitch and stress and other non-segmentals are integral to the meaning of utterances.

- Changed: The child varies one or more of the non-segmental features of the model utterance.

- Same: The child produces an exact repetition of the non-segmental features of the model utterance.

In each subcategory, changed or the same, the echoic response is coded as being either a complete or an incomplete repetition:-

- a complete repetition indicates that the child repeats the entire model utterance,

- an incomplete repetition indicates that the child echoes only a part of the model utterance.

\section{RATERS USED TO CONTROL OBSERVATION}

The utterances were analyzed independently by the examiner and the resident speech clinician to objectify observations. After being trained on the significant features of the categorical system, the resident speech clinician viewed the first video-recording of interaction with each child. The interjudge reliability was measured by comparison of the results obtained by the examiner and the resident speech clinician. Non-paràmetric statistical procedures were used due to the small number of subjects used in the experiment.

\section{RESULTS}

\section{INTERJUDGE RELIABILITY}

Non-parametric statistical procedures determined that a high agreement $(97,34 \%)$ existed between the paired judgements of the examiner and the second judge, indicating that the categorical system designed by the examiner was a practical and easy to use scale. The reliability of this analysis procedure therefore seems to be high. 


\section{CATEGORIZATION OF THE UTTERANCES}

Figure 1 represents a summary of the data obtained from the categorization of the autistic children's echoic and non-echoic utterances. It demonstrates a tendency for a greater occurrence of immediate echolalia $(61,2 \%)$, followed by initiation $(36,9 \%)$ and only a token usage of delayed echolalia $(1,9 \%)$. There is a marked difference between verbal versus verbal and non-verbal turn-taking; verbal and non-verbal turns being the most prevalent $(81,9 \%)$. It can be seen that other-directed utterances had a higher rate of occurrence $(85 \%)$ than self-directed utterances $(15 \%)$, but for both these categories most utterances were rated as relevant. It is interesting to note that $87,5 \%$ of the other-directed utterances were rated as relevant whereas only $66,7 \%$ of the self-directed utterances were relevant; suggesting (tentatively) that other-directed utterances are more likely to be rated as relevant than are self-directed utterances.
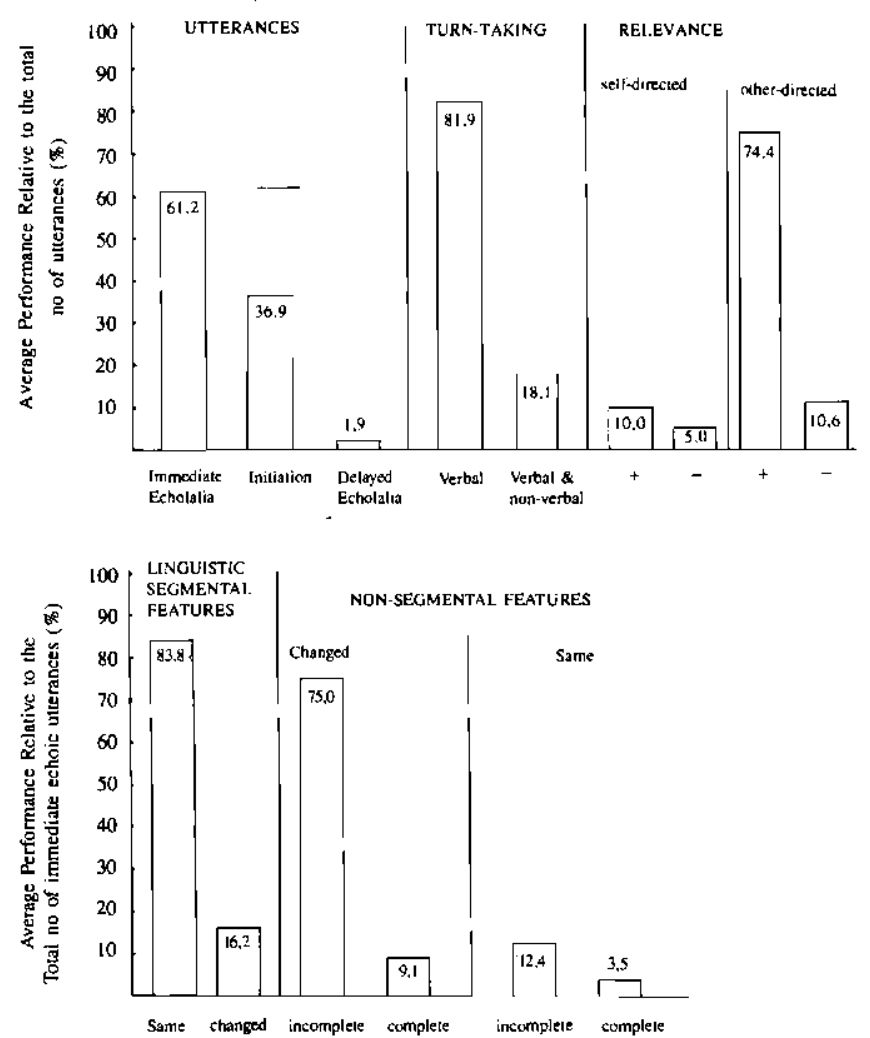

Figure 1 Categorization in percentages of the autistic subjects' echoic and non-echoic utterances.

The data shows that the linguistic segmental features of the immediate echolalic utterances were mostly rated as the same $(83,8 \%)$, rather than as changed $(16,2 \%)$. The non-segmental features of the immediate echolalia were more often rated as changed with only an incomplete repetition of the model utterance $(75 \%)$. The incidence of the use of the same non-segmental features with a complete repetition of the model utterance was minimal $(3,5 \%)$.

The data presented in Figure 1 initiated the calculation of the information in Figure 2. The relevance of the children's utterances is reviewed including a more specific analysis of the relevance of the immediate echolalia.

Echoic and non-echoic utterances viewed together had a higher incidence of being rated as relevant $(84,4 \%)$ in comparison to only $15,6 \%$ of these utterances being rated as irrelevant. A more specific analysis of the immediate echolalia showed a large difference be-
Rejevance of the Utterances

\% Relative to the total no of utterances
Relevance of the Immediate Echolalía

$\%$ Relative to total no of Immediate echoic utterances

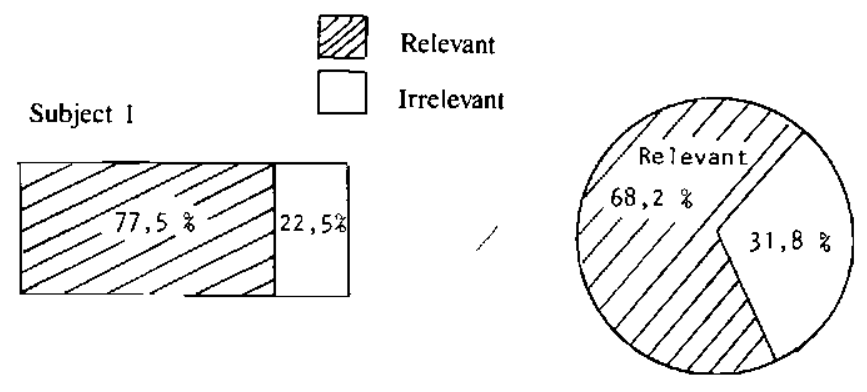

Subject 2
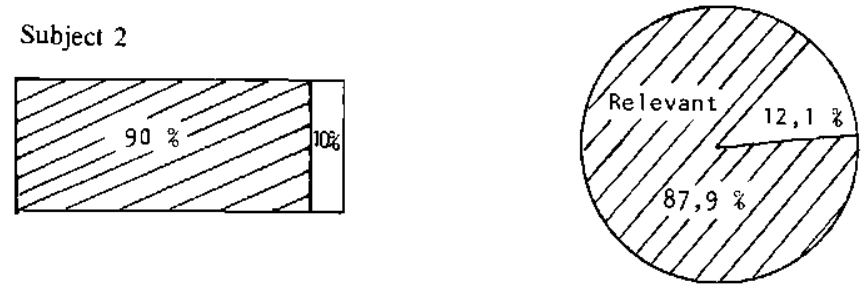

Subject 3
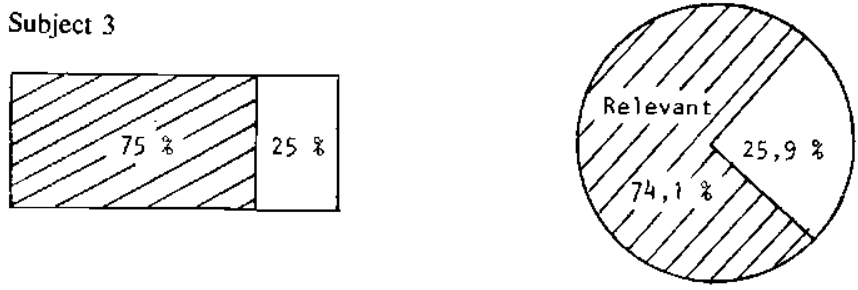

Subject 4
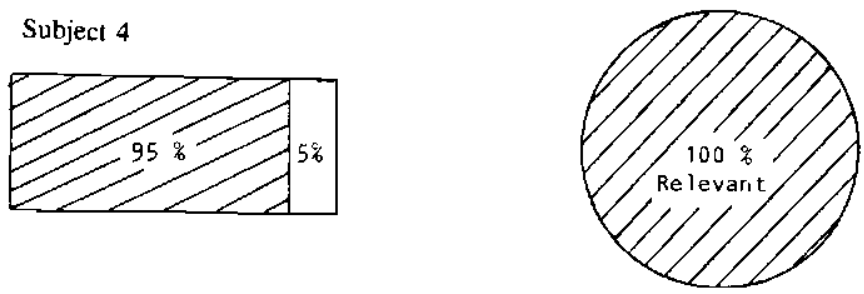

Figure 2 Analysis of the relevance of the utterances

tween the ratings of relevance and of irrelevance. Of the immediate echolalia, $82,6 \%$ was relevant whereas only $17,5 \%$ was rated as irrelevant.

Specific analysis of each individual subject's performance was carried out and summarized into a single table (Table 3 ) indicating each subject's performance as a percentage relative to the total number of utterances.

A brief comparison of the subjects' performances according to the data in Table 3 indicates that Subject 4 has the highest initiation of original utterances $(55 \%)$, followed by $40 \%$ immediate echolalia and only $5 \%$ delayed echolalia. Of these utterances, $95 \%$ were rated as relevant and $100 \%$ of the immediate echolalia was rated as relevant. It is interesting to note that Subject 4 had the highest mental status for all four subjects ( 36 months) and was the oldest subject. Subject 2's performance shows very little initiation $(17,5 \%)$, no delayed echolalia and a high incidence of immediate echolalia. Subject 2 was, at the time of the study non-testable and mental status could not be determined. Subject 1 and 3 display the same general tendencies of more initiation than delayed echolalia and the majority of utterances being immediate echolalia $(55 \%$ and $67,5 \%$ respectively). They also show a high rate of relevant utterances and relevant immediate echolalia. 
Table 3 Performance of subjects on each category

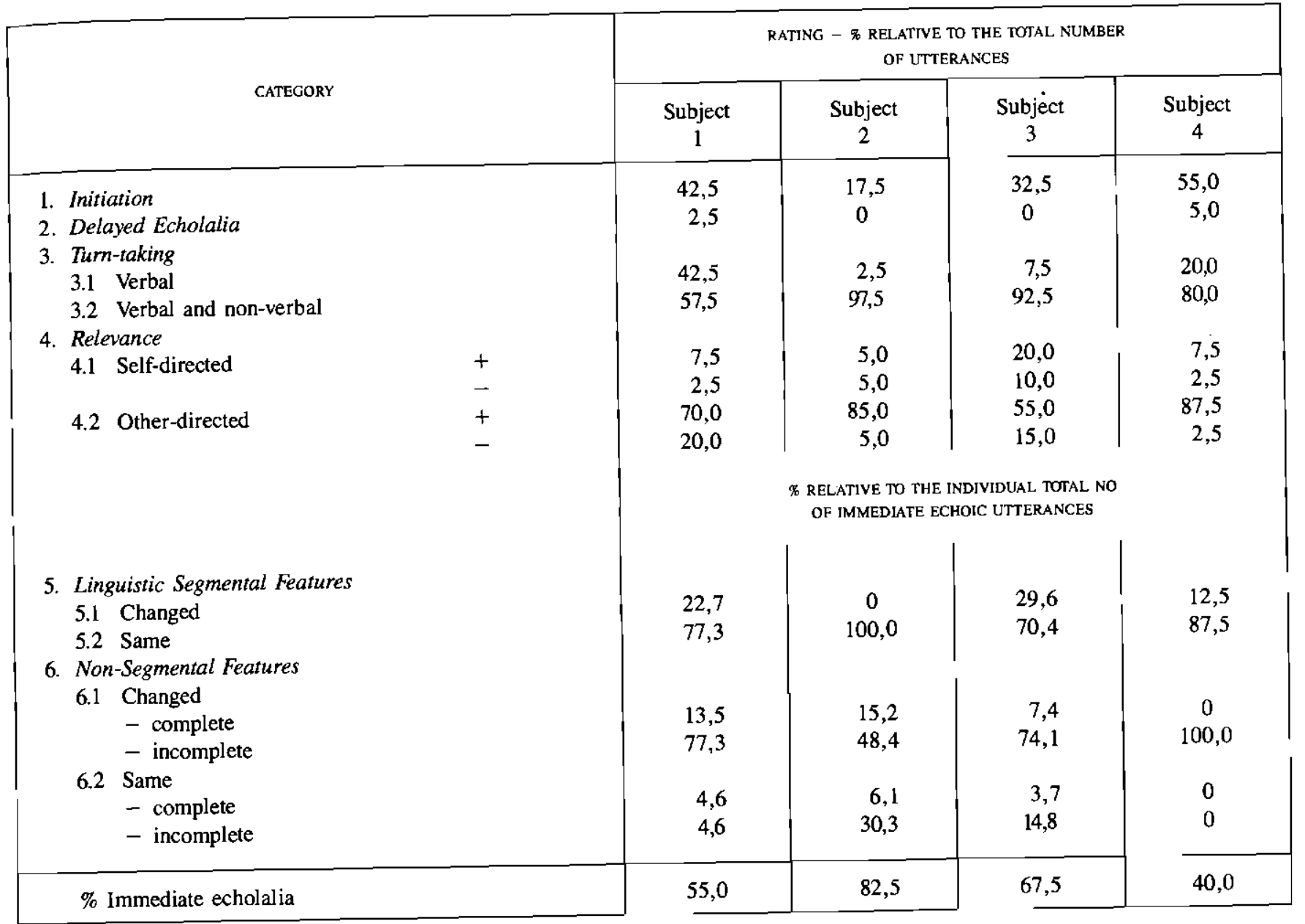

The range of the four subjects' performances indicates interesting tendencies as well as variance among their performances. In the category of initiation, Subject 2 scored $17,5 \%$ whereas Subject 4 scored $55 \%$, pointing out that a large variance exists in the intersubject performance. This could possibly be related to the variance between these subjects' mental ages. The average of the 4 subjects' performances in initiation $(36,9 \%)$ is therefore not indicative of the individual scores. A broader inspection of Subject 2's and Subject 4's overall performance shows that Subject 2 has $82,5 \%$ immediate echolalia compared to Subject 4 's $40 \%$ rating; a difference of $42,5 \%$. However, in the case of relevance both these subjects (2 and 4) have the highest percentage of utterances rated as relevant, that is $90 \%$ and $95 \%$ respectively. Therefore the ápparent difference in performance in production of the type of utterance does not necessarily affect the rating of relevance of the subjects' utterances.

A relatively small range of performance exists between the four subjects' production of delayed echolalia, the highest score being $5 \%$ (Subject 4 ) and the lowest rating $0 \%$ (Subjects 2 and 3 ). The category of turn-taking indicates a wider range of performance among the subjects. Subject 1 has $42,5 \%$ verbal turns compared to $57,5 \%$ verbal and non-verbal turns. The remaining subjects show a much greater difference between these two sub-categories with a higher incidence of verbal and non-verbal turns. For example, Subject 2 has 2,5\% verbal turns compared to $97,5 \%$ verbal and non-verbal turns. The data supports a general tendency of a greater percentage occurrence of verbal and non-verbal turns.

In the category of relevance there is a small range between the subjects' performances indicating a general tendency for a greater preva- lence of other-directed utterances $(85 \%)$ and the large majority of both self-directed and other-directed utterances being rated as relevant $(84,4 \%)$.

There is a degree of variance between the subjects' performances in the category of linguistic segmental features. Subject 2 produced all his immediate echolalia with the same linguistic segmental features of the model utterances. Subject 3 produced the greatest change in the linguistic segmental features $(29,6 \%)$ of the model utterances. There is however a general tendency for the four subjects to display the same linguistic segmental features of the model utterance. Characteristic for all the subjects is the general tendency for nonsegmental features of the immediate echoic utterances to be more often changed and incomplete repetitions of the model utterance.

The percentage production of immediate echolalia differs among the subjects. Subject 2 produced the most immediate echolalia $(82,5 \%)$ whereas Subject 4 produced the least immediate echolalia ( $40 \%$ ), but both subjects have the highest ratings of relevance, that is $84,9 \%$ and $100 \%$ of their immediate echolalia was rated relevant respectively. Subject 1 who produced the most verbal (only) turns $(42,5 \%)$ produced the least relevant immediate echolalia $(68,2 \%)$. However comparison of the individual subject's relevant and irrelevant immediate echolalia indicates a general tendency of a greater percentage occurrence of relevant immediate echolalia.

\section{DISCUSSION}

The general attitude toward autistic immediate echolalia is to view it as an automatic and meaningless repetition of words, and not as 
the child's attempt to initiate and sustain social contact (Fay, 1980) or to communicate his intentions. The high occurrence of immediate echolalia is coupled with the finding that $85 \%$ of these echoic responses were rated as relevant, meaningful and an atternpt at communication within their iirnited capabilities. In response to, "Gaan jy nou saamwerk?" Subject 4 replied "Saamwerk", while smiling and making rare eye contact with the interlocutor. Subject 4 changed the non-segmental features of the model utterance and made a siatement of the word he echoed and did not copy the questioning tones of the model utterance. He clearly displayed his intention to the interlocutor through the manipuiation of an immediate echoic response accompanied by non-verbal cues of eye-contact and smiling.

In the interaction analyzed by the examiner, the children always responded to a question or a statement directed at them by the interlocutor. Acceptance and expansion of echoic behaviour appeared to reinforce the autistic child's turn-taking echoes and utterances.

Important non-verbal communication co-occurred with the otherdirected utterances providing indicators of intent whereby the utterances could be rated. These responses can be interpreted in terms of attention, need for interpersonal feedback and an attempt at sustaining the flow of interaction (Argyle, 1973).

A comparison of the individual subjects' performance shows some interesting differences. A brief comparison shows Subject 4, the oldest subject producing the most initiation, less immediate echolalia and no delayed echolalia; whereas Subject 2 displayed the least initiation, no delayed echolalia and the most immediate echolalia. This suggests that Subject $\mathbf{4}$ has more advanced language skills as shown by his ability to produce more initiated utterances and fewer echoic responses supporting the view of Carr, Schreibman and Lovaas (1975) that immediate echolalia may be an early stage in the development of normal language functioning. Of great importance is the fact that a very small difference existed between these two subjects in relation to the relevance of their echoic and non-echoic utterances; Subject 2 displayed 90,0\% rclevance and Subject 4, 95,0\% relevance. This suggests that the relevance of the autistic child's echoic and non-echoic utterances is not necessarily dependent on the child's level of speech and language development.

Subject 3 produced the greatest change in the linguistic segmental features of the model utterance, using some of the interlocutor's words and adding elements to indicate his own meaning. Prizant and Duchan (1982) view this type of immediate echolalia as probably the most intentional and least automatic response and an example of intentional mitigation. Subject 3's performance may be influenced by the fact that he received speech therapy to expand receptive and expressive language and had a mental status of 29 months.

The examiner recognizes that analysis of the child's utterances alone is a limitation of the study. Analysis of the interlocutor's utterances would provide interesting and relevant information related to the type of response made by the child. However, a bricf survey of the interlocutor's utterances shows that when the interlocutor repeated a child's relevant immediate echoic response and the child echoed the interlocutor, the child's second echo was more likely to be rated as irrelevant. This suggests that the speech clinician should take care not to inhibit the child's relevant utterances by producing meaningless repetitions of the child's echoes.

\section{IMPLICATIONS FOR DIAGNOSIS AND TREATMENT}

The findings of this study should be regarded within the greater framework of diagnosis and treatment of the autistic child. As previ- ously cited, bchaviourally orientated researchers (Koegal, Lovaas and Schreibman, 1974) consider echolalia a communication disorder and advocate the extinction or replacement of echolalic behaviours through the use of behaviour modification procedures (Lovaas, 1977). The findings of this study dispute a non-functional view of immediate echolalia.

The consideration of immediate echolalia as having communicative intent must form an integral part of diagnosis and therapy. The clinician should guard against regarding a high occurrence of echoic utterances in the child as indicating less meaning than a higher $o$ currence of non-echoic utterances, but should rather view echolalia as possibly a necessary stage of language development for verbal autistic children (Philips and Dyer, 1977).

According to Prizant \& Duchan (1982), indiscriminate extinction of all forms of immediate ccholalia is ill-advised because of the functions that echolalia may serve for autistic children. Individual differences do exist and each child has a ccrtain potential to learn to communicate. Different therapeutic procedures should be used to treat, for example, a child who has been predominantly echolalic for some years than those used to treat a child who displays comprehension and communicative intent with the echoic utterances he produces. The latter child nceds to accept and exploit immediate echolalia and leam to relate the repetitions to aspects of the environmert and communicative interactions (Prizant \& Duchan, 1982).

\section{REFERENCES}

Argyle, M. The Psychology of Interpersonal Behavioun Penguin Books Ltd, Harmondsworth, Great Britain, 1973.

Argyle, M. Social Interaction. Tavistock Publications Ltd, London, Great Britain, 1973.

Carr, E., et al. Control of Echolalic Speech in Psychotic Speech. J. Abnor. Child Psycho., 3, 331-338, 1975.

Clancy, H., et al. The Diagnosis of Infantile Austism. Develop. Med. Child Neuro, 11, 432, 1969.

De C. Murray, C.H., A Report of the Committee of Enquiry into the Treatment, Education and Care of Autistic Children. Department of National Education, Government Print, Pretoria, RSA, R.P. $26 / 72,1971$.

Dore, J. Requestive, Systematic Nursery School Conversation. In: Campbell, R. and Smith, R., (Eds.), Recent Advances in the Psychology of Language. Plenum Press, New York, 1978.

Fay, W.H. On the Echolalia of the Blind and of the Autistic Child. J. Speech Hean Disord., 38, 478-489, 1973.

Fay, W.H. Aspects of Language. In: Fay, W.H. and Schuler, A.L., (Eds.) Emerging Language in Autistic Children. Language Intervention Series, Vol 5, Edward Arnold Ltd, London, Great Britain, 1980.

Hurtig, R., Ensrud, P, and Tomelin, B. The Communicative Function of Question Production in Autistic Children. J. Autism Develop. Disord., 12, 57-69, 1982.

Koegal, R., Lovaas, O.I. and Schreibman, L. A Behaviour Modification Approach to the Treatment of Autistic Children. $J$. Autism Child. Schizoprenia. 4, 111-116, 1974.

Lovaas, O. The Autistic Child: Language Development Through Behaviour Modification. Halstead Press, New York' 1977.

Philips, G. and Dyer, C. Late Onset Echolalia in Autism and Allied Disorders. Br. J. Disord. Commun., 12, 47-59, 1977.

Prizant, B.M. and Duchan, J.F. The functions of Immediate Echolalia in Austistic Children. J. Speech Hear. Disord., 47, 241-249, 1982.

Prutting, C.A. Pragmatics as Social Competence. J. Speech Hear. Disord., 47, 123-134, 1982. 
A Stuttering Therapy Programme with Spastic Dysphonia - a Single Case Study

Rutter, M. The Development of Infantile Autism. J. Psychol. Med. 9. 147-163, 1974.

Schuler, A.L. Aspects of Communication. In: Fay, W.H. and Schuler, A.L., Emerging Language in Autistic Children. Language Intervention Series, 5, Edward Arnold Ltd, London, Great Britain, 1080
Tough, J. The Development of Meaning: A Study of Children's Use of Language. George Allen and Unwin Ltd, London, Great Britain, 1977.

Wing, L. Early Childhood Autism: Clinical, Educational and Social Aspects. A Wheaten and Co., Exeter, Great Britain, 1976. 